\title{
Replacement of Lateral Line Sensory Organs during Tail Regeneration in Salamanders: Identification of Progenitor Cells and Analysis of Leukocyte Activity
}

\author{
Jay E. Jones and Jeffrey T. Corwin \\ Department of Neuroscience and Department of Otolaryngology-Head and Neck Surgery, School of Medicine, University \\ of Virginia, Charlottesville, Virginia 22908
}

\begin{abstract}
It has been proposed that supporting cells may be the progenitors of regenerated hair cells that contribute to recovery of hearing in birds, but regeneration is difficult to visualize in the ear, because it occurs deep in the skull. Hair cells and supporting cells that are comparable to those in the ear are present in lateral line neuromasts, and in axolotl salamanders these cells are accessible to microscopic observation in vivo. After amputation of a segment of the tail that contains neuromasts, cells from the posteriormost neuromast on the tail stump divide rapidly and form a migratory regenerative placode. The cells of the regenerative placode represent a lineage that eventually produces both hair cells and supporting cells in replacement neuromasts. We sought to identify the progenitors of the regenerative placode by using differential interference contrast microscopy combined with time-lapse video recording in living axolotl salamanders. In response to amputation, the mantle-type supporting cells at the posteroventral edge of the neuromast that is nearest to the wound increased their frequency of cell division, and gave rise to the first cells of the placode. The increase in mitotic activity of mantle-type supporting cells was accompanied by an unexplained decrease in the frequency of divisions in the same neuromast's population of internal supporting cells.
\end{abstract}

The time-lapse records suggested that the changes in the mitotic activity of supporting cells might have been linked to the presence of phagocytic leukocytes in the vicinity of the neuromast that was nearest to the wound. Leukocytes were evenly distributed around control neuromasts, but during regeneration leukocyte activity increased significantly in the vicinity of the posterior half of the posteriormost neuromast. The redistribution of leukocytes occurred early in

\footnotetext{
Received Feb. 3, 1992; revised Aug. 25, 1992; accepted Sept. 15, 1992.

We thank Matthew Kelley, Akiko Katayama, Ph.D., and Mark Warchol, Ph.D., for their assistance in carrying out these experiments, and for discussions that improved the work in general. Thanks also to Arlene Trader for invaluable administrative assistance, and to Christine Laverack and Ava Krol for technical assistance. Special thanks to Nell Cant, Ph.D., Department of Neurobiology, Duke University, and Miriam Henson, Ph.D., Department of Cell Biology and Anatomy, University of North Carolina at Chapel Hill, for their generous donations of laboratory space and supplies. Thanks to Susan Duhon and the staff of the Indiana University Axolotl Colony for helpful, discussions and a reliable supply of axolotls. Finally, J.E.J. thanks thesis committee members Jeremy Tuttle, Ph.D., Dave Hill, Ph.D., Sally Moody, Ph.D., and Marilyn Fisher, Ph.D., for their support, patience, and scientific insights. This work was supported by a Research Career Development Award and a grant from NIDCD, and funds from the Lions of Virginia Hearing Foundation to J.T.C

Correspondence should be addressed to Jay E. Jones, Cato Research Ltd., 4364 South Alston Avenue, Durham, NC 27713.

Copyright (C) 1993 Society for Neuroscience $0270-6474 / 93 / 131022-13 \$ 05.00 / 0$
}

the regenerative response, but a causal role for the leukocytes has not been conclusively established. It is possible that the leukocytes could contribute to the formation of the regenerative placode at that location by breaking down the glycocalyx that ensheaths the outermost cells of the neuromast, or through the secretion of mitogenic growth factors.

[Key words: amphibia, hair cells, hearing, macrophage, time-lapse microscopy, wound repair]

In mammals, sensory hair cells of the inner ear are believed to be produced only during embryonic development (Ruben, 1967; Bredberg, 1968). Losses of hair cells resulting from exposure to loud sound, or from poisoning by aminoglycoside antibiotics and chemotherapy agents, produce deficits in hearing or balance that have been considered irreversible. This apparent inability to replace damaged hair cells in mannuls contrasts with the continual postembryonic production of hair cells that occurs in the ears of fish and amphibians and in the vestibular epithelia in the ears of birds (Corwin, 1981, 1983, 1985; Popper and Hoxter, 1984; Jørgensen and Mathiesen, 1988). In birds, tritiated thymidine experiments have demonstrated that regenerative replacement of hair cells also occurs (Corwin and Cotanche, 1988; Ryals and Rubel, 1988). It has been proposed that supporting cells that survive at the sites of lesions may be the progenitors of the replacement hair cells. Supporting cclls appear to be the only resident cell type in lateral line neuromasts after the hair cells have been selectively killed, yet those neuromasts are able to regenerate hair cells (Balak et al., 1990). However, direct demonstrations of the cell lineages that lead to replacement hair cells in the ear have been difficult to accomplish. For this reason, we have used the lateral line system of the axolotl salamander Ambystoma mexicanum as a model to investigate what cell lineages lead to the production of sensory hair cells during regeneration.

The mechanoreceptive sensory epithelia of the lateral line are punctate collections of sensory hair cells and supporting cells called neuromasts. Neuromasts are embedded in the epidermis, but share many aspects of development (Landacre, 1921; Stone, 1922, 1933), cellular morphology (Jørgensen and Flock, 1973; Flock and Jørgensen, 1974; Kimura, 1975), peripheral and central innervation (Fritzsch and Wahnschaffe, 1987; Meredith and Roberts, 1987), and physiology (Flock et al., 1973; Hudspeth, 1985 ) with the auditory and vestibular epithelia of the ear. In axolotl salamanders, the lateral line neuromasts reside in the epidermis along the surface of the thin, transparent tail. They can be observed directly with excellent resolution in living axolotl salamanders. 
In aquatic amphibians, amputation of the tip of the tail evokes a series of events that lead to regeneration of the lost portion of the tail and replacement of approximately the same number of neuromasts as were removed. The replacement neuromasts appear to arise from the progeny of cells that originate in the distalmost neuromast remaining on the tail stump (Stone, 1933, 1937; Speidel, 1947; Wright, 1947; Corwin, 1986; Corwin et al., 1989). A mass of undifferentiated cells, the regenerative placode, extends from that neuromast and migrates posteriorly, where it gives rise to new hair cell epithelia (Fig. 1). Limitations in light microscopy, vital staining, and transplantation of embryonic tissues, the techniques available in the past, have left doubt about the specific identity of the cell lineage that initially produces the regenerative placode. We report a reinvestigation that has employed differential interference contrast (DIC) microscopy combined with time-lapse video recording to follow the early cellular events in the regeneration of lateral line sensory epithelia.

\section{Materials and Methods}

Embryonic and juvenile axolotl salamanders of the pigment-deficient "white" and "albino" strains were obtained from the Indiana University Axolotl Colony and kept in $20 \%$ (embryos) or $50 \%$ (juveniles) Holtfreter's solution at $10^{\circ} \mathrm{C}$. The low temperature was used to retard growth until the animals were needed for experimentation. Axolotls used in experiments ranged in size from 17 to $25 \mathrm{~mm}$ total length, and a supply of animals in that size range was acclimated to room temperature for several days prior to each experiment. After hatching, axolotls were placed in 50\% Holtfreter's solution and fed live brine shrimp larvae. For microscopic observations and amputation surgery, axolotls were anesthetized by immersion in $100 \%$ Holtfreter's solution containing $0.007 \%(\mathrm{w} / \mathrm{v})$ benzocaine (ethyl- $p$-aminobenzoate). The distal $1-2 \mathrm{~mm}$ of the tail, containing two to four neuromasts, was amputated while observed with a dissection microscope. After the amputation, salamanders remained anesthetized and were transferred to a chamber for longterm observation. Some operated axolotls were allowed to recover from anesthesia and were maintained in 100\% Holtfreter's solution until the delayed start of time-lapse observations of the later stages of regeneration.

Time-lapse observation. Prior to use in time-lapse experiments, salamanders were examined to ensure that the plane of amputation was more than $75 \mu \mathrm{m}$ from the posteriormost neuromast remaining on the tail stump. For time-lapse observations, the salamanders were placed in a sealed observation chamber (Fig. $2 A$ ). The upper and lower surfaces of the chamber consisted of $24 \times 60 \mathrm{~mm}$ coverglasses of no. 1.5 thickness. Two strips of adhesive-backed magnetic tape were affixed to the bottom coverglass where they magnetically anchored minuten pins that held the tail flat against the chamber bottom. Sterile Holtfreter's solution containing anesthetic and $5 \mathrm{~mm}$ HEPES buffer ( $\mathrm{pH} 7.7$ ) was passed continuously through the chamber by a gravity feed at $200-250 \mathrm{ml} / \mathrm{hr}$. At $24-48 \mathrm{hr}$ intervals, the chamber was disassembled and cleaned, and the salamander was allowed to recover from anesthesia and was fed. The salamander was then reanesthetized and replaced in the chamber, usually within $2 \mathrm{hr}$ of its release, so that the experiment continued.

Time-lapse records were made with a Zeiss IM inverted microscope, which was modified by inserting an electronic shutter between the light source and the condenser (Fig. $2 B$ ). Two pairs of heat-absorbing and heat-reflecting filters, and a handpass green filter (586-591 nm width) were in the light path. A planachromate $40 \times, 0.65$ N.A. objective lens, DIC optics, and a Newvicon video camera (Hamamatsu model C2400) were used. Video images were initially recorded using a time-lapse videocassette recorder (Gyyr model TLC 2051) at a setting that gave a record in which events were sped up by a factor of 120 when played back. A DC motor, reduction gears, and a locomotive-type eccentric wheel were linked to the focus knob of the microscope to continuously vary focus through the thickness of the epithelia. Later experiments were improved through the use of an optical memory disk recorder (OMDR; Panasonic model TQ2028F). When recording to optical disks, a microcomputer-based image processing system (Image-1/AT, Universal Imaging Corp.) was used for video frame summation, digital contrast enhancement, and mathematical sharpening of cell borders in

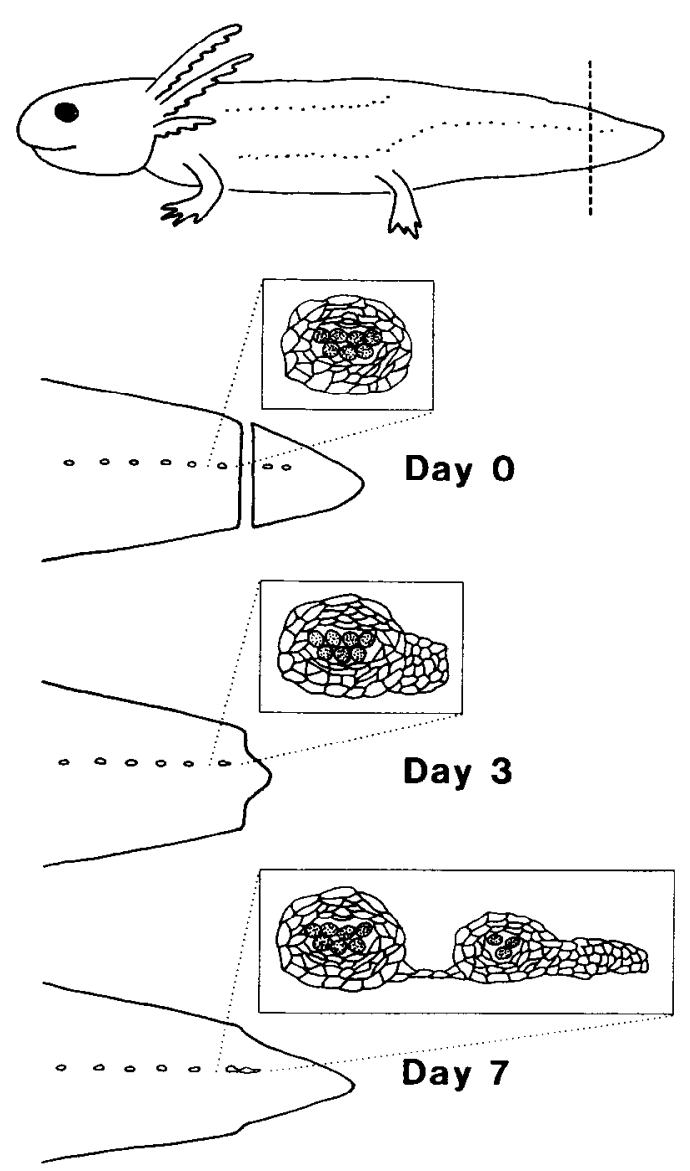

Figure 1. Schematic representation of lateral line regeneration in the axolotl. In the top drawing, the level of amputation of the tip of the tail is indicated by the broken vertical line, and neuromasts of the posterior lateral line system by dots. The appearance of the animal's tail as it regrows is shown in the drawings below. The posteriormost neuromast on the tail stump, with its newly forming regenerative placode, is shown in the insets at three stages following amputation. As the tail regrows, the posteriormost neuromast responds by producing the undifferentiated cells of the regenerative placode at its posterior edge. The data presented in this report conclusively identify mantle-type supporting cells as the cell type that seeds the regenerative placode.

the digitized video images prior to recording. The image processing system also controlled the electronic shutter, the OMDR, and a microstepper motor (Superior Electric Co. type M063-LE09 with Centent model CN1043 driver) that was linked to the focus knob of the microscope. Video images from at least three levels of focus were recorded sequentially on separate tracks of the optical disks. At intervals of 150 sec, the shutter opened and exposed the specimen to the light source for $1 \mathrm{sec}$ while 16 video frames were digitized and summed, and then the shutter closed while the digitized video image was enhanced. The processed image was recorded to an address on the optical disk, and then the microstepper motor adjusted the microscope to a new programmed focal plane and the image capture and recording cycle was repeated. In that way, it was possible to produce time-lapse records concurrently for each level of focus through the tissue. Photographs or prints from video images were made with a video graphic recorder (Matrix Systems) or a color video printer (Sony model UP5000).

Analysis of time-lapse data. Lateral line neuromasts were selected so that all were roughly the same size, containing approximately $15-20$ hair cells, 40-50 internal supporting cells, and 20-30 mantle-type supporting cells. For analysis of events, neuromasts were divided into four quadrants along anterior-posterior and dorsal-ventral axes. The number of cell divisions, the types of cells involved, and their locations were tabulated from time-lapse records of normally growing (control) and regenerating (experimental) lateral line sensory epithelia. The patterns of activity of two types of leukocytes were quantified by tabulating their 


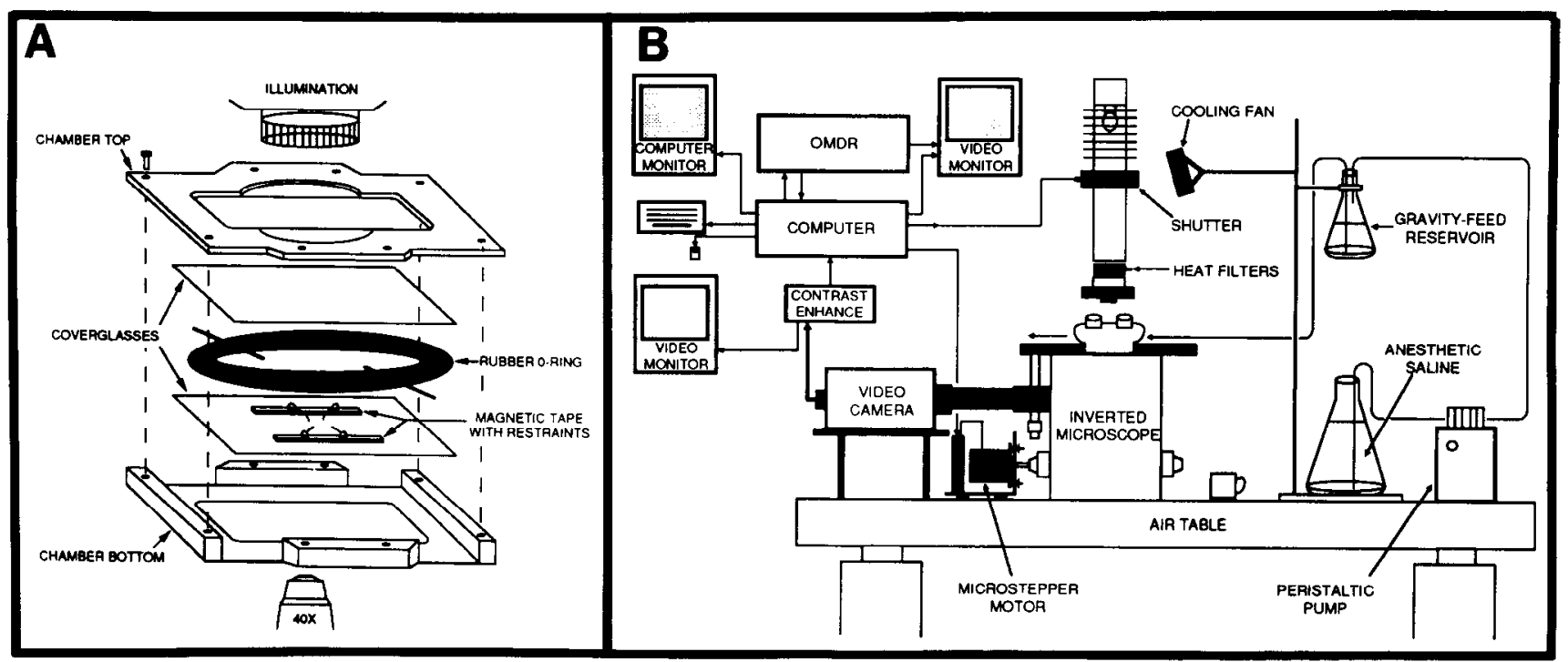

Figure 2. Technical approach to viewing individual neuromasts of the lateral line. $A$, The axolotl viewing chamber. The upper and lower halves of the chamber are milled from aluminum, and when fastened together with screws, compress a rubber O-ring between two coverglasses, forming an enclosed space. Anesthetic solution flows through two lengths of polyethylene tubing connected to hypodermic needles that pierce the $\mathrm{O}$-ring. $B$, Apparatus used for visualization and time-lapse video recording of cell behaviors in lateral line epithelia. An anesthetic-saline solution flows continuously by gravity through a chamber placed on the microscope stage in which the axolotl is restrained (see $A$ ). DIC images obtained with an inverted microscope are diverted to a video camera. The analog video signal is adjusted for optimal contrast and enhanced digitally using a microcomputer-based image processor, and then the image is recorded using an OMDR. The computer controls an electronic shutter placed in the light path of the microscope, a microstepper motor linked to the fine focus adjustment knob of the microscope, and the OMDR.

number and their locations at $1 \mathrm{hr}$ intervals throughout the time-lapse records. Dividing cells and leukocytes that were at the boundary between two quadrants were scored as 0.5 per quadrant.

IIematology and histochemistry. IIematological and histochemical screening methods for identification of leukocyte subtypes in amphibians were used (Hadji-Azimi et al., 1987; Turner, 1988). Blood samples were obtained by heart puncture from three anesthetized juvenile axolotls. Smears were treated with Wright's stain and observed under bright-field illumination. Histochemical protocols that differentiate between leukocytes were used to investigate the blood smears, so as to aid in the further identification of the small and large leukocytes observed in the time-lapse recordings. Histochemical localization of nonspecific esterase, chloroacetate esterase, and myeloperoxidase in leukocytes of the axolotl tail was carried out on tails from 25 juvenile axolotls. Tissues were fixed in $100 \%$ Holtfreter's solution that contained 3\% paraformaldehyde, $1.25 \%$ glutaraldehyde, and $0.1 \mathrm{~m}$ phosphate buffer at $\mathrm{pH}$ 7.4. Histochemical protocols and reagents supplied with cytochemistry kits for differentiation of leukocyte types were used (Sigma, CP-1 and 181-B). Substrate markers for nonspecific esterase activity primarily label monocytes and macrophages, whereas markers for chloroacetate esterase activity primarily label granulocytes ( $\mathrm{Li}$ et al., 1973). Neutrophilic leukocytes contain large amounts of myeloperoxidase as part of their bactericidal arsenal, and can be identified on the basis of the content of that enzyme (Kaplow, 1965).

The tissue-wide response of leukocytes to tail amputation was assessed by counting cells that stained for chloroacetate esterase and myeloperoxidase in a series of axolotl tails. The tips of their tails were amputated under anesthesia, and four animals per group were fixed at $0,1,3,5$, and $7 \mathrm{~d}$ following the amputation. A camera lucida drawing of the outline of the distal $2-3 \mathrm{~mm}$ of each tail was made and the positions of all stained leukocytes were charted. Small and large leukocytes were counted separately in five transverse bands that began at the amputation site and continued anteriorly. The bands were each $0.1 \mathrm{~mm}$ wide (anterior-posterior) and $2 \mathrm{~mm}$ in height, spanning the mid-axis of the salamander's dorsal-ventral plane. In cases in which tails had undergone regenerative growth and remodeling at the amputation site, the bands were drawn parallel to the contour of the posterior edge of the tail.

\section{Results}

Time-lapse recording allowed nearly continuous observation of lateral line neuromasts in vivo in healthy axolotl salamanders for as long as $11 \mathrm{~d}$. Throughout any one recording session, the image of a neuromast could change either because it shifted from the level of focus or because the specimen moved laterally out of the field of view. Therefore, it was necessary to check the focus and positioning of the image of the neuromast at least every $2 \mathrm{hr}$ while an experiment was in progress. A number of experiments were aborted because one or both of these parameters were not maintained. Only those experiments in which a continuous record was obtained are reported below. During rest periods, animals normally recovered from anesthesia within 30 min and began feeding. Experiments were usually continued within $2 \mathrm{hr}$. The overall shapes of cells, the detailed characteristics of the cytoplasm and nuclei, and the positions of cells relative to each other were all consistent before and after a break. Time-lapse recording at multiple levels of focus throughout the $50 \mu \mathrm{m}$ thickness of a neuromast further contributed to the ability to continue observations with corresponding images before and after a break (Fig. 3). All cell types, including sensory hair cells, maintained their characteristic morphologies during these experiments. The timing of the onset of regeneration was similar to that in salamanders that were exposed to intermittent anesthesia and microscopic observation. Vigorous blood flow was visible in the tissue below the neuromasts, and the branches of the lateral line nerve that contacted the neuromasts appeared normal throughout the observations.

Neuromasts of the posterior lateral line of the axolotl consist of as many as 30 hair cells surrounded below and on the sides by supporting cells. The sensory hair cells are characterized by spherical nuclei, apical hair bundles, and a central location within the epithelium. Hair cells do not reach the base of the neuromast, but supporting cells do. Transmission electron microscope studies have shown that two types of supporting cells can be reliably distinguished in these neuromasts: internal supporting cells and mantle-type supporting cells (Flock, 1965; Jørgensen and Flock, 1973; Flock and Jørgensen, 1974). In the present 

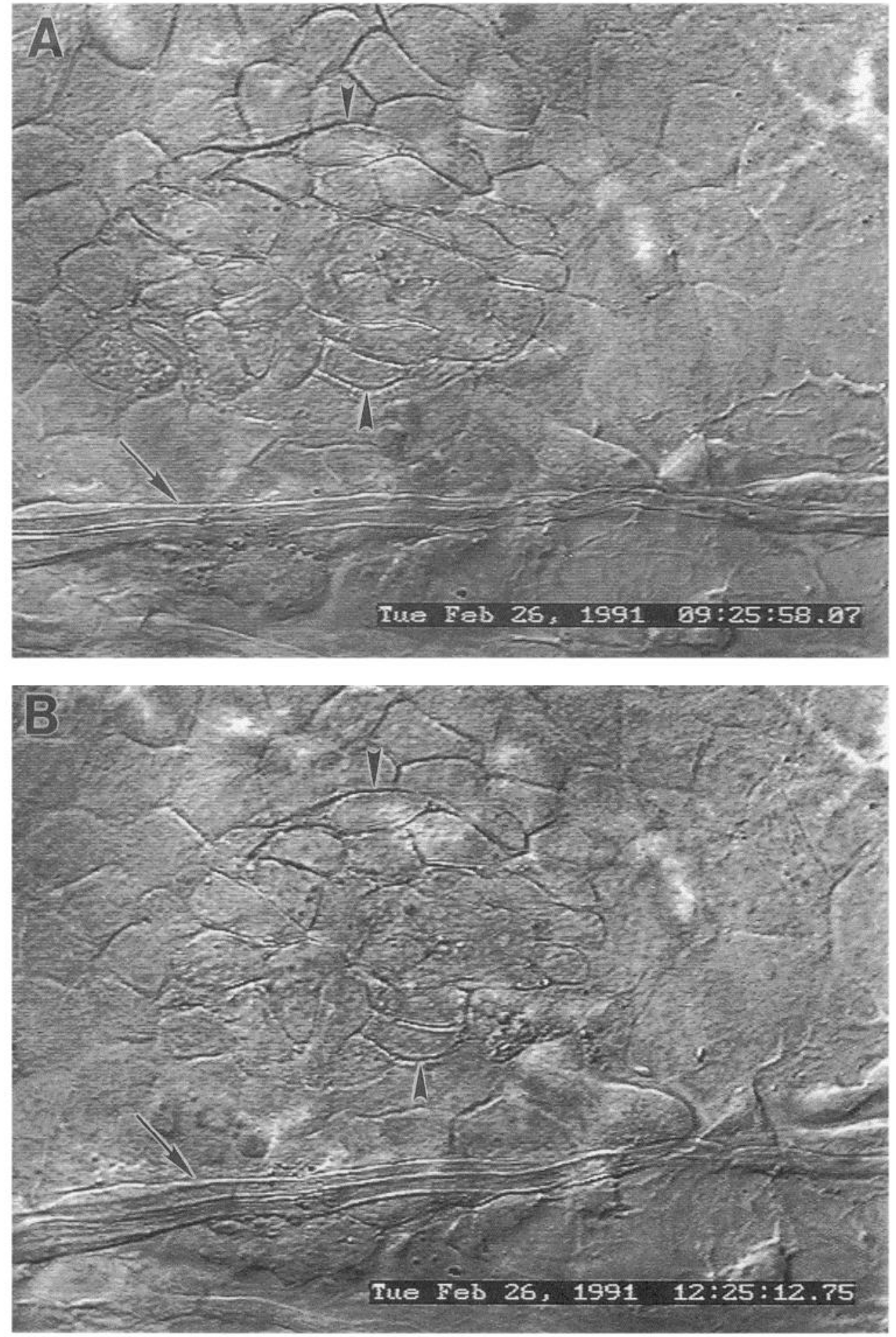

Figure 3. Relocalization of a lateral line neuromast following a break in time-lapse recording. $A$, Video print of the last image taken of a neuromast prior to a break in time-lapse recording in which the observation chamber was cleaned and the animal was fed. The image corresponds to a level of focus at the basal layer of supporting cells in the neuromast. $B$, The first time-lapse image recorded of the same neuromast as in $A$, following the $3 \mathrm{hr}$ break in recording. Images $A$ and $B$ share many detailed features, including the distinctive shapes of two supporting cells at the dorsal and ventral edges of the neuromast (arrowheads), and the contour of the lateral line nerve (arrows). Timestamp bar, $110 \mu \mathrm{m}$. study, the distinction between supporting cell subtypes was made on the basis of position within the neuromasts (Fig. 4). Internal supporting cells are located in positions in which they could make physical contact with hair cells, lying either directly beneath the hair cells or along side of them. Mantle-type supporting cells form a rind of cells that surrounds the outside of the internal supporting cells and hair cells. One to three layers of mantle-type supporting cells usually separate the neuromast from the epidermis in juvenile salamanders. Internal supporting cells and mantle-type supporting cells may lie at opposite ends of a continuum of cell types. There is no one morphological feature, such as a distinct type of organelle or pigmentation, that could be used to distinguish mantle-type supporting cells from internal cells. Nonetheless, these two cell types have been reliably distinguished by us and by a number of other authors on the basis of their difference in position. Data outlined below suggest that the internal supporting cells and the mantle-type supporting cells can also be distinguished on the basis of different responses to events that trigger regeneration. However, it should be noted that the light microscopic observation methods that 

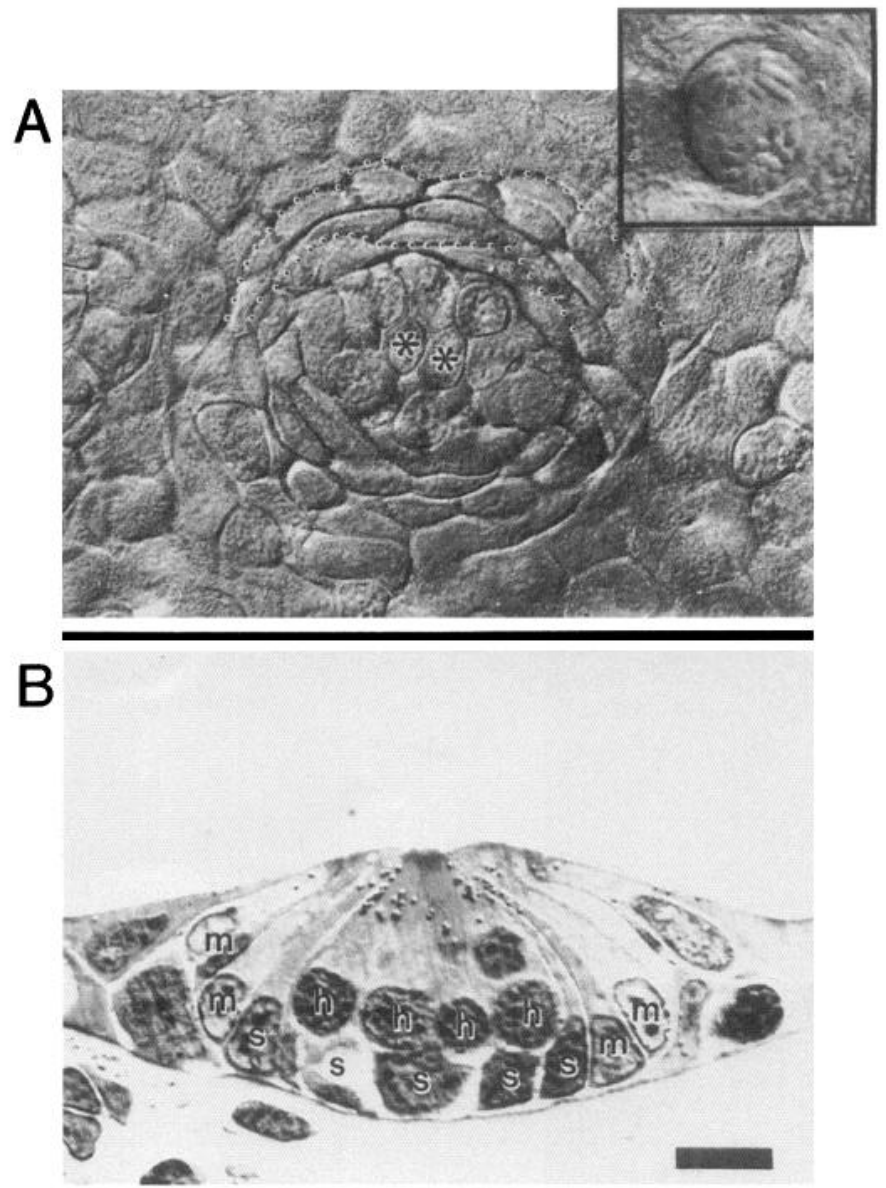

Figure 4. Relative positions and morphologies of hair cells, internal supporting cells, and mantle-type supporting cells in neuromast sensory epithelia of the lateral line system. A, DIC view of a neuromast in the skin of an axolotl salamander. Asterisks indicate the centrally positioned, nearly circular outlines of two of nine hair cell nuclei visible. Broken lines enclose the dorsal portion of the region of the neuromast occupied by mantle-type supporting cells. The lines were omitted from the ventral half of the neuromast for comparison. Internal supporting cells lie inside the mantle-type supporting cell region, and occupy positions either directly adjacent to, or beneath, the hair cells. Inset, High-magnification view of a supporting cell in anaphase of mitosis. $B$, Transverse histological section through a neuromast. Internal supporting cells $(s)$ contact hair cells $(h)$ from below and on the sides. Mantle-type supporting cells $(m)$ lie peripheral to the internal supporting cells and hair cells. Scale bar, $20 \mu \mathrm{m}$.

allowed the long-term recording of cell behaviors in this investigation left some room for doubt about whether a particular supporting cell should have been classified as an internal type or a mantle type in a very small percentage of the cases studied. The observed differences between cell behaviors for those two types of supporting cells far exceeded the small number of cells where there was some ambiguity as to the correct subcategory of supporting cell type. Figure 4 is provided and labeled with examples of the distinction between internal supporting cells and mantle-type supporting cells so that the reader can see how we distinguished between the two subcategories of supporting cells for the analysis.

Mantle-type supporting cells were easily distinguished from the surrounding epidermal cells on the basis of size, shape, and epithelial stratification. Epidermal cells are two to three times larger than supporting cells and polygonal-shaped. The epi- dermis is composed of two layers of cells, and those cells have a squamous form. In contrast, mantle-type supporting cells are smaller and their outlines are lenticular or oval-shaped when viewed from the skin surface. Each mantle-type supporting cell reaches from the base of the neuromast to its apex (Jørgensen and Flock, 1973). All cell types that could potentially contribute progeny to lateral line regeneration were continuously monitored by the method of time-lapse recording, with images taken at multiple planes of focus, so we are confident that supporting cells were accurately distinguished from epidermal cells.

Mitoses. Dividing cells were recognizable from early stages because they separated from neighboring cells and became spherical (Fig. 4A, inset). Condensation of chromosomes during prophase was followed by the alignment of chromosomes in a metaphase plate that rocked back and forth through an arc of approximately $20^{\circ}$. The rocking subsided just prior to separation of the chromosomes in anaphase. The only cells within lateral line epithelia that were observed to divide were supporting cells; we never observed divisions of hair cells. Durations of prophase through cytokinesis were measured in internal supporting cells, mantle-type supporting cells, and placodal cells. In controls, the average durations of prophase through cytokinesis of internal supporting cells and mantle-type supporting cells were similar (Table 1). Following tail amputation, the average duration of prophase through cytokinesis of mantle-type supporting cells was shorter than that of internal supporting cells $(p<0.005$, Student's $t$ distribution). The average duration of prophase through cytokinesis of newly formed placodal cells was shorter than that of both internal supporting cells and mantle-type supporting cells $(p<0.005)$.

Control neuromasts. The pattern of mitotic activity in control neuromasts is illustrated in Figure 5. The numbers of mitoses that occurred in one neuromast during the first $24 \mathrm{hr}$ of timelapse observation in each of six salamanders were pooled. Twenty-three of the 26 cell divisions observed $(88 \%)$ were in the internal population of supporting cells; the remaining three cell divisions were in the mantle-type supporting cells. The differences in the number of mitoses among the quadrants were not statistically significant. A similar pattern of mitotic activity was recorded in another experiment in which a neuromast that was four neuromasts anterior to the site of a tail amputation wound was observed in time-lapse microscopy for a period of more than $50 \mathrm{hr}$ (data not shown).

Neuromasts responding to tail amputation. Following amputation of the tip of the tail, the posteriormost neuromast that remains on the tail stump responds by giving rise to a regenerative placode. The timing of the onset of placode formation is somewhat variable, but in most cases a regenerative placode is first recognizable approximately $72 \mathrm{hr}$ after the amputation. Three trends were apparent in data pooled from six cases in which the regenerative placode initially formed between 72 and $96 \mathrm{hr}$ after amputation (Fig. 5). First, significantly fewer mitoses occurred within the internal supporting cell population in experimental neuromasts as compared to controls ( 7 vs 23 cell divisions in $144 \mathrm{hr}$ of cumulative observation; $p<0.01$, Student's $t$ distribution). Second, there was a large increase in the mitotic activity of the mantle-type supporting cells in experimental neuromasts as compared with controls (60 vs 3 cell divisions in $144 \mathrm{hr}$ of observation). Third, the number of mantle-type supporting cell mitoses was significantly greater in the two posterior quadrants than in the two anterior quadrants ( $p$ $<0.01)$. There was a highly significant increase in the number 
Table 1. Duration of prophase through cytokinesis (minutes)

\begin{tabular}{lll} 
& \multicolumn{2}{l}{ Treatment } \\
\cline { 2 - 3 } Cell type & Control & Tail-tip amputation \\
\hline Internal SC & $101 \pm 6.5(n=27)$ & $111 \pm 8.2^{*}(n=24)$ \\
Mantle-type SC & $96 \pm 8.5(n=8)$ & $86 \pm 3.2^{*}(n=95)$ \\
Placode & NA & $77 \pm 1.1^{*}(n=157)$
\end{tabular}

SC, supporting cell.

${ }^{*} p<0.005$.

of mantle-type supporting cell mitoses observed in the posteroventral quadrant, as compared to the other quadrants $(p<$ $0.001)$.

Figure 6 illustrates three stages in the formation of a regenerative placode, based on time-lapse observations of the posteriormost neuromast that remained on the tail stump after 1 $\mathrm{mm}$ of the tip of the tail was amputated. One internal supporting cell divided $23 \mathrm{hr}$ after amputation, and another divided at 31 hr. One mantle-type supporting cell in the dorsal region of the neuromast divided at $38 \mathrm{hr}$. The first sign of placode formation occurred at $48 \mathrm{hr}$ when a mantle-type supporting cell at the posteroventral edge of the neuromast divided. Over the next 3 $\mathrm{hr}$, four more mantle-type supporting cells divided at the posteroventral edge of the neuromast (Fig. $6 B$ ). Thirteen more divisions of mantle-type supporting cells occurred during the next $24 \mathrm{hr}$. Ten of the 13 cells were at the posteroventral edge of the neuromast. Those divisions of mantle-type supporting cells resulted in the seeding of a small placode that extended posteriorly from the original posteroventral edge of the neuromast. Cells that were outside the original boundary of the neuromast divided as early as $72 \mathrm{hr}$ after the amputation (Fig. $6 \mathrm{C}$ ). The cells of the placode divided frequently (Table 1) as they formed a longitudinally extending band that was three or four cells wide in the dorsoventral axis. The dorsal and ventral boundaries of the placode were well defined.

Cell divisions, cell growth, and cell migrations all contributed to the posterior advance of the regenerative placode. The placodal cells migrated independently and their movements were generally in the posterior direction, but anteriorly directed motility and dorsally and ventrally directed movements were also observed in the placodal cells (Fig. 7). The rate of locomotion of placodal cells ranged up to $40 \mu \mathrm{m} / \mathrm{hr}$. The time-lapse images of motile placodal cells showed membrane ruffling that was reminiscent of the ruffling of motile fibroblasts in cell culture (Abercrombie et al., 1970).

Leukocytes. Leukocytes were present in the vicinity of neuromasts from the start of all time-lapse recordings. The presence of leukocytes in the fields of view was not significantly affected by either positive or negative phototactic responses to the $1 \mathrm{sec}$ periods of microscopic illumination employed in the time-lapse experiments. In each of six control salamanders, a single neuromast was observed during $24 \mathrm{hr}$ of time-lapse recording. The average number of leukocytes observed in each field of view during the four $6 \mathrm{hr}$ periods of observation ranged from 17.1 \pm 2.7 to $20.3 \pm 3.5,20.5 \pm 2.9$, and $16.8 \pm 4.5$ in consecutive order.

The range of leukocyte phenotypes observed in axolotl salamanders probably reflects the presence of various combinations of mononuclear phagocytes (monocytes, macrophages), granulocytes (polymorphonuclear neutrophilic, eosinophilic, and basophilic leukocytes), and lymphocytes. The variations in phe-
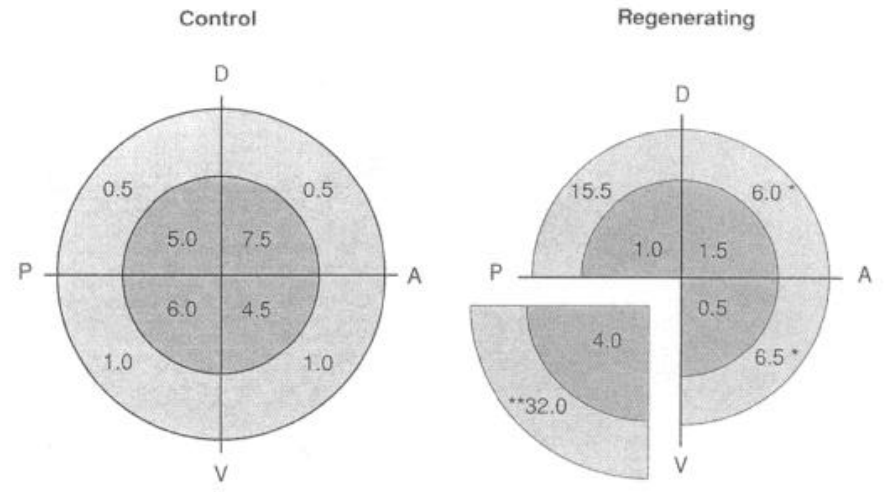

Figure 5. Mitotic activity in lateral line sensory epithelia. Neuromasts are depicted as concentric circles. The area within the inner circle represents the population of internal-type supporting cells, and the area between the inner and outer circles represents the mantle-type supporting cell population. Neuromast schematics are divided into four quadrants based upon the anterior-posterior and dorsal-ventral axes. Control, Mitoses in normally growing (control) neuromasts. Numbers represent pooled mitoses occurring in each region during the initial $24 \mathrm{hr}$ of observation in six salamanders ( $144 \mathrm{hr}$ total observation time). Regenerating, Mitotic activity in neuromasts participating in lateral line regeneration. Pooled mitoses for the distalmost neuromast remaining on the tail stump following amputation of the tip of the tail at time 0 in six salamanders is depicted for the $24 \mathrm{hr}$ time interval from 72 to 96 $\mathrm{hr}$ following the amputation (144 hr total observation time). Internal and mantle-type supporting cell populations are represented as in controls, except that the posteroventral quadrant is shown detached for emphasis. ${ }^{*}, p<0.01 ;{ }^{* *}, p<0.001$; probabilities of obtaining observed counts assuming a Poisson distribution for the data.

notypes may also reflect the presence of mononuclear phagocytes in different states of activation. Upon entering extravascular tissues, mononuclear phagocytes pass through several morphologically distinct stages as they differentiate from monocytes to inflammatory macrophages, and ultimately to activated macrophages (Riches et al., 1988)

Smears of axolotl blood that were treated with Wright's stain demonstrated lymphocytic, monocytic, and granulocytic lineages. Cells that appeared to be lymphocytes were round in shape, with round nuclei and a very small amount of cytoplasm that stained dark blue. Cells that were identified as monocytes were also round in shape, with slightly indented nuclei and relatively more cytoplasm than lymphocytes. Granulocytes had bi-lobed or multi-lobed nuclei, and contained numerous granules that stained blue to purple. No cells that had a preponderance of eosinophilic granules were observed.

Histochemical protocols for differentiating between leukocytes were modified for use in whole-mount preparations of axolotl tails (Fig. 8). Cells resembling the small leukocytes of time-lapse records stained positively for nonspecific esterase, chloroacetate esterase, and myeloperoxidase to various degrees. By extension of criteria that have been validated for leukocytes in mammals, this suggests that the small leukocytes consisted of monocytes and neutrophilic granulocytes. Cells that were strongly positive for nonspecific esterase resembled the large motile cells in the time-lapse recordings. These cells stained moderately to weakly for chloroacetate esterase, and usually showed no staining for myeloperoxidase. The staining pattern suggested that the large leukocytes were macrophages. However, it was not possible to distinguish confidently all small leukocytes as one cell type and all large leukocytes as another cell type, because the patterns of histochemical staining overlapped be- 


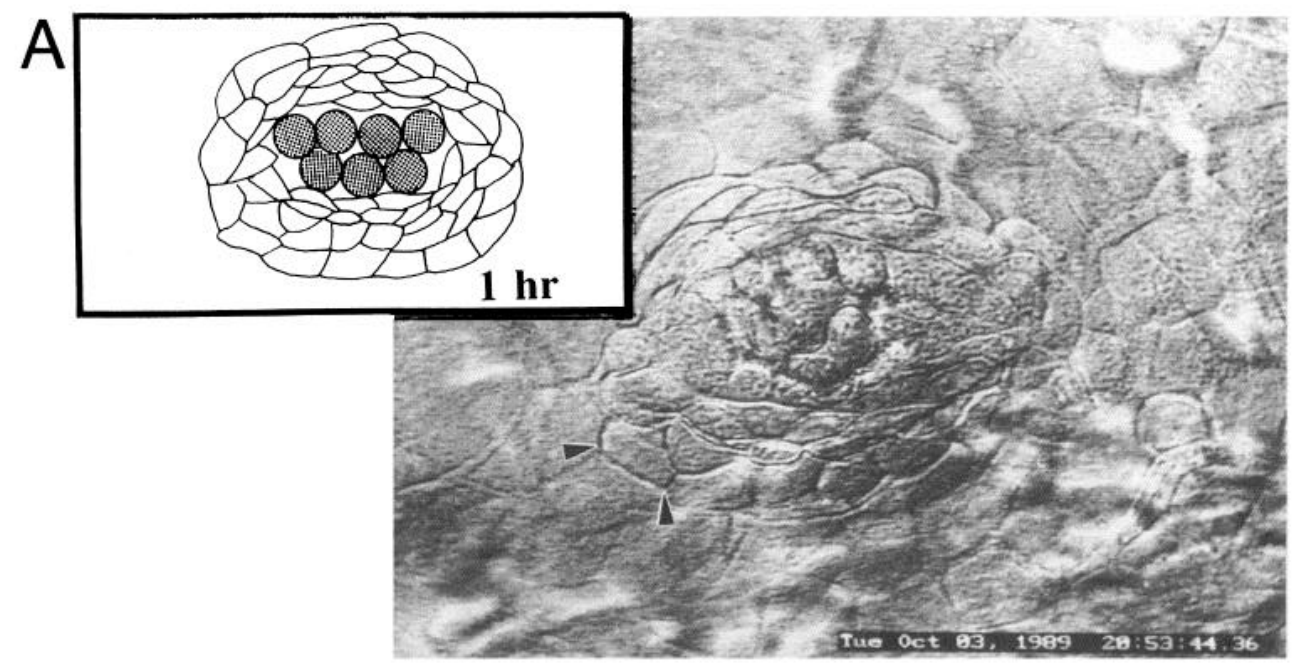

Figure 6. Early mitotic events in regenerative placode formation. $A$, The appearance under DIC optics of the distalmost neuromast on the left side of an axolotl $1.5 \mathrm{hr}$ after tail-tip amputation. Arrowheads indicate a mantle-type supporting cell on the posteroventral edge of the epithelium. $B$, The same neuromast approximately $48 \mathrm{hr}$ after tail-tip amputation. The arrow indicates a mantle-type supporting cell in mitosis just prior to cytokinesis in approximately the same position as the cell in $A$. $C$, The appearance of the neuromast approximately $27 \mathrm{hr}$ after the image in $B$ was taken. The arrowheads mark the boundary of the newly forming regenerative placode. The arrow indicates a mitotic cell within the placode. Insets, Tracings showing the approximate positions of mitoses occurring during the time intervals indicated, in the same neuromast shown in the video images. Note the sudden onset of mitotic activity that occurs in the mantle-type supporting cells on the posterior side of the neuromast, particularly in the posteroventral region, during the 48-51 hr time interval after tailtip amputation. Later mitoses occur in cells that lie outside of the original borders of the neuromast. The positions of three of these cell divisions observed during the time interval from 71 to 75 hr postamputation are shown. These cells represent the earliest members of the placode. The orientation of the mitotic asters depicted are as they occurred in the time-lapse record. Timestamp bar, $110 \mu \mathrm{m}$.
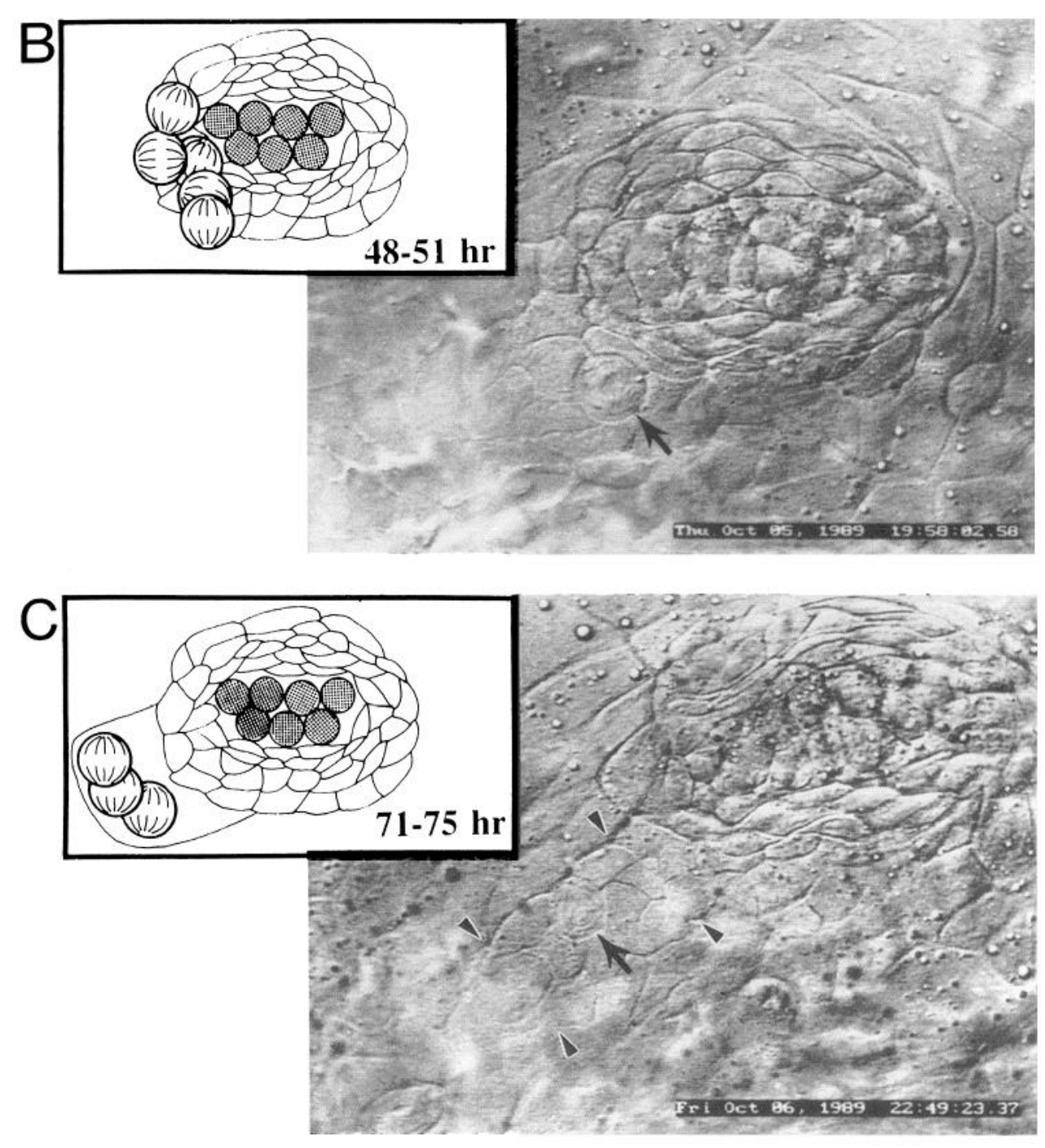

tween the two size classes. It is possible to be confident that types of cells that were positively identifiable as macrophages and other cells that were positively identifiable as granulocytes were both intimately associated with lateral line epithelia.

Leukocytes moved among the cells in the neuromasts and the surrounding tissues. The population of leukocytes was hetero- geneous, ranging from cells of $10-15 \mu \mathrm{m}$ diameter with few pseudopodia, to cells of $30-40 \mu \mathrm{m}$ diameter that possessed numerous pseudopodia and refractile cytoplasmic inclusions. For data analysis, leukocytes were categorized as either "small" or "large," with the size distinction arbitrarily placed at a maximum cell diameter of $25 \mu \mathrm{m}$. Both categories of leukocytes 


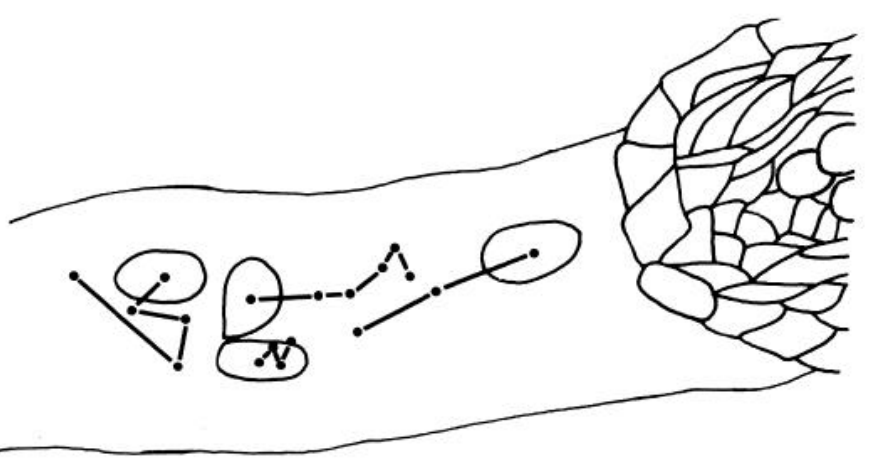

Figure 7. Individual motility and paths of migration of placodal cells. This tracing from the video record shows the posterior half of the distalmost neuromast on the tail stump of an axolotl $5 \mathrm{~d}$ after a tail-tip amputation. The two lines extending horizontally from the neuromast represent the dorsal and ventral boundaries of the regenerative placode. The outlines of four cells within the placode, and the migratory paths taken by each of those cells are shown. Each dot on the lines representing the paths of migration corresponds to the distance migrated during 3 $\mathrm{hr}$ of observation. The outlines of the remainder of the densely packed cells of the placode are omitted for clarity.

showed an amoeboid type of locomotion. The small leukocytes were seldom stationary, and were capable of speeds in excess of $200 \mu \mathrm{m} / \mathrm{hr}$. The appearance of small leukocytes in time-lapse recordings is illustrated in Figure 9 . The routes of migration followed by small leukocytes indicated that they recognized the boundary between neuromasts and the surrounding epidermis. This can be seen in the representative examples of migratory paths followed by small leukocytes illustrated in Figure 10.

Large leukocytes migrated as rapidly as small leukocytes at some times, but were more often stationary for long periods when they were near the outer edges of neuromasts. The large leukocytes extended and retracted pseudopodia, removing cells from the epithelium and phagocytizing them (Fig. 11). Internal supporting cells and mantle-type supporting cells, but not hair cells, were phagocytized in control neuromasts (Table 2). After tail amputation, there was an increase in the incidence of phagocytosis of mantle-type supporting cells in the posteriormost neuromast on the tail stump relative to the incidence of phagocytosis of mantle-type supporting cells in controls ( $p<0.01$; Table 2$)$. Within neuromasts responding to tail amputation, there was a significantly greater incidence of phagocytosis of mantle-type supporting cells than of internal supporting cells $(p<0.01)$. Cells that were phagocytized usually were not obviously distinguishable from their neighbors prior to being engulfed. Large leukocytes often appeared to interact with other leukocytes. When this occurred, the cells moved directly toward one another, extended pseudopodia, and apparently made contact. Small leukocytes also appeared to make cell-to-cell contacts, but did not phagocytize other cells.

Leukocyte redistribution during lateral line regeneration. The numbers and locations of small and large leukocytes were tabulated at $1 \mathrm{hr}$ intervals throughout an initial $24 \mathrm{hr}$ period of time-lapse recording for a single neuromast in each of six control salamanders (144 hr cumulative observation). Time-lapse recordings of the posteriormost neuromast participating in lateral line regeneration during the $72 \mathrm{hr}$ after tail amputation were made in four salamanders and analyzed similarly ( $288 \mathrm{hr} \mathrm{cu}-$ mulative observation). The locations of leukocytes were charted by estimating the positions of their centroids within each of the
A

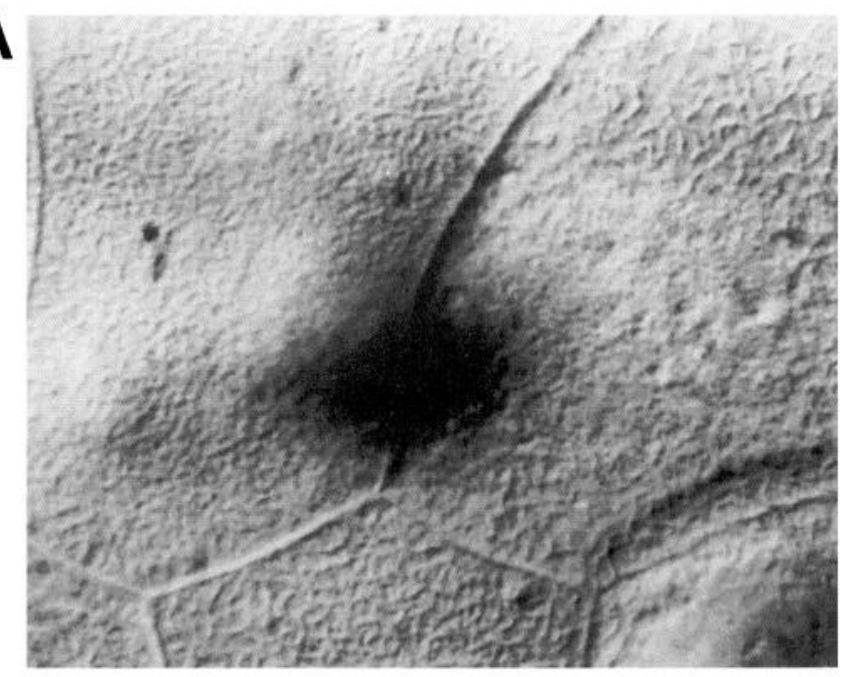

B

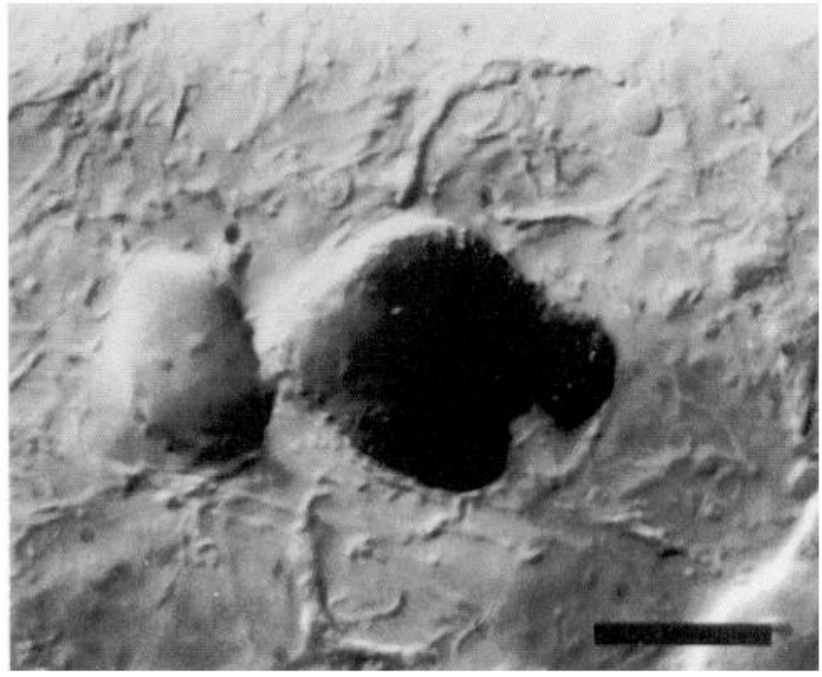

Figure 8. Histochemical localization of a leukocyte-specific enzyme: DIC views (100× magnification) of a myeloperoxidase-positive leukocyte in the tail of an axolotl salamander. $A$, Level of focus at the epidermis. A histochemically labeled cell is seen out of the focal plane, below the epidermis. $B$, Same field at the level of focus containing the myeloperoxidase-positive leukocyte. Histochemical protocols for the localization of the leukocyte-specific enzymes chloroacetate esterase and $\alpha$-naphthyl butyrate esterase (nonspecific esterase) were also carried out. Scale bar, $5 \mu \mathrm{m}$.

four quadrants formed by visually dividing the neuromasts along dorsal-ventral and anterior-posterior axes. The positions were specified further by noting whether the leukocytes were in the tissue peripheral to the neuromasts, within the $170 \mu \mathrm{m} \times 230$ $\mu \mathrm{m}$ field of view, or among the mantle-type supporting cells of the neuromasts, or among the internal supporting cells and hair cells of the neuromasts. Average numbers of each subtype of leukocyte counted during each $12 \mathrm{hr}$ segment of time-lapse observation were calculated (Fig. 12). In both control neuromasts and in neuromasts that were participating in lateral line regeneration, small leukocytes were more prevalent than large leukocytes. The majority of the small leukocytes were in the tissue peripheral to the neuromasts. An intermediate number of small leukocytes were in the regions of mantle-type supporting cells. Small leukocytes seldom penetrated the layers of mantle-type supporting cells to approach internal supporting cells and hair 
A

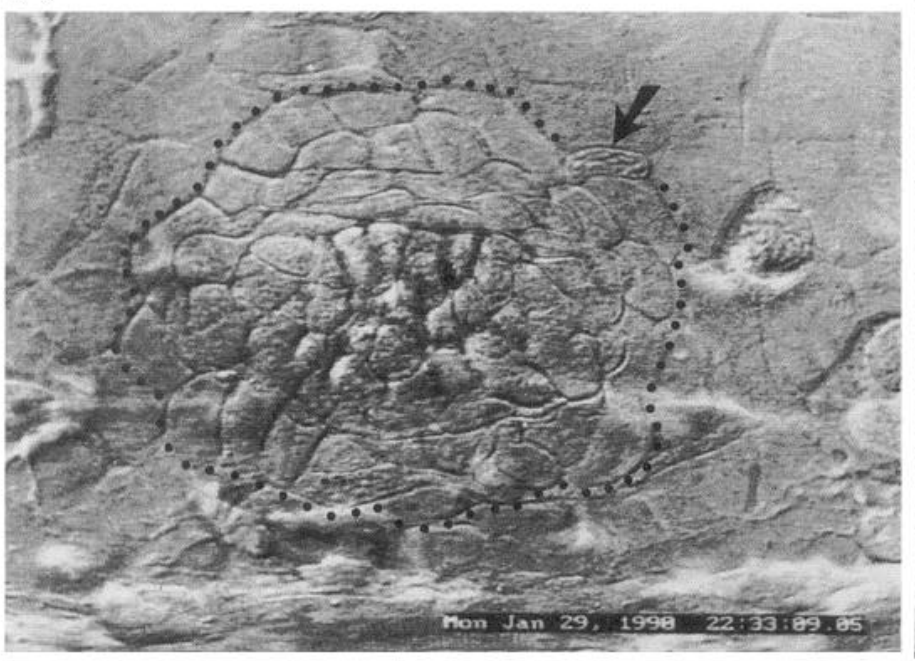

B

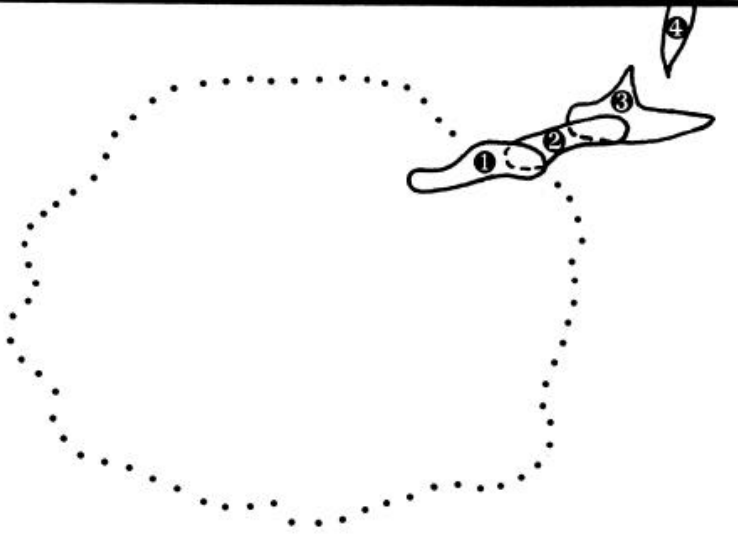

Figure 9. Morphology and migratory behavior of a "small" leukocyte. $A$, DIC view from the time-lapse video record of a neuromast, whose boundary is demarcated by the broken line, and the position of one of several small leukocytes in the field of view (arrow). $B$, Schematic representation of the same neuromast, and the outlines of the same leukocyte at three subsequent time points over a 30 min period. Note the shape of the leukocyte and its position relative to the neuromast changes. During the $30 \mathrm{~min}$ of observation presented, the cell traveled approximately $80 \mu \mathrm{m}$, corresponding to a velocity of $160 \mu \mathrm{m} / \mathrm{hr}$. Time-stamp bar, $110 \mu \mathrm{m}$.

cells. After amputation, more large leukocytes were observed in the vicinity of neuromasts participating in lateral line regeneration.

When all of the leukocyte observations within individual

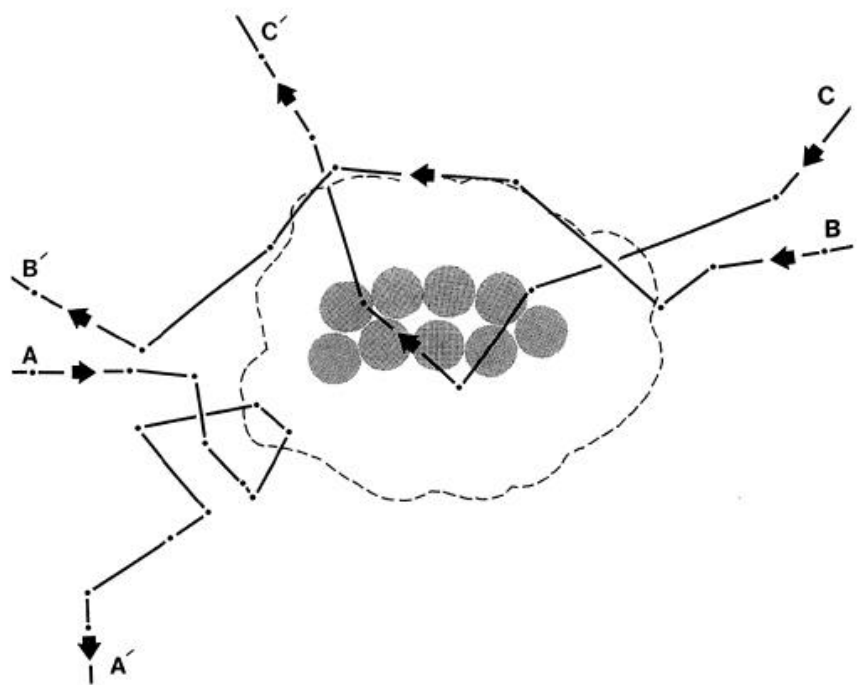

Figure 10. Traces of three common types of migratory paths observed in "small" leukocytes. The border of a neuromast that is participating in regeneration is indicated by the broken line. The shaded circles represent the approximate positions of sensory hair cells. The time elapsed between individual points on the lines representing each path was 15 min. $A$ and $A^{\prime}$, The path of a leukocyte that entered the field of view from the posterior side of the neuromast and contacted the mantle-type supporting cells at its posteroventral edge. The leukocyte lingered at that area before exiting the field of view. $B$ and $B^{\prime}$, The path of a leukocyte that entered the field of view and, upon contacting the mantletype supporting cell region of the neuromast, followed the boundary of the epithelium until it reached the opposite side, then continued on in its original direction. It appears in these cases that the neuromast represents an obstacle in the path of the leukocyte as it continues on to some other destination. $C$ and $C^{\prime}$, The migratory path of a leukocyte that penetrated the neuromast before leaving the field of view. quadrants were pooled, no quadrant or hemisphere contained a significantly larger number of leukocytes than any other quadrant under control conditions (Fig. 12). In contrast, when neuromasts were participating in lateral line regeneration, there was a statistically significant increase in the average number of leukocytes on the posterior side of the neuromast $(p<0.01$; Fig. 12). Cells that originate from that side of the neuromast give rise to the regenerative placode.

We hypothesized that the increased numbers of leukocytes that were observed on the posterior sides of those neuromasts might have resulted from a general redistribution of leukocytes throughout the tail in response to some attraction toward the site of the amputation wound. Tail amputation wounds were created in 16 axolotls, and the distribution of histochemically stained leukocytes was determined relative to the locations of the wounds to test for such a global redistribution (Fig. 13). Following tail-tip amputation at time 0 , there were roughly four large leukocytes and eight small leukocytes in each of a series of five 100- $\mu \mathrm{m}$-wide bands of tail tissue that were sampled extending anteriorly from the edge of the wound. Both types of leukocytes increased in numbers with time following wounding, with the greatest numbers of leukocytes present in all of the bands on the third day after amputation. In the posteriormost band that included the tail amputation wound, the numbers of large and small leukocytes had begun to increase by $24 \mathrm{hr}$. The more anterior bands either had little or no increases at that time. At $24 \mathrm{hr}$ the numbers of small and large leukocytes both reached approximately 3.5 times the numbers that had been present at the time of the amputation. At the third sampling point, on the third day following the amputation, the posteriormost band contained 32 small leukocytes and 46 large leukocytes on average. Those numbers represent four times the number of small leukocytes and a continuation of the dramatic increase in the number of large leukocytes to over 11 times the number that were initially present in the tissue. The numbers of leukocytes in the other bands generally decreased with increasing distance from the wound site. At the time of the fourth sampling period, 


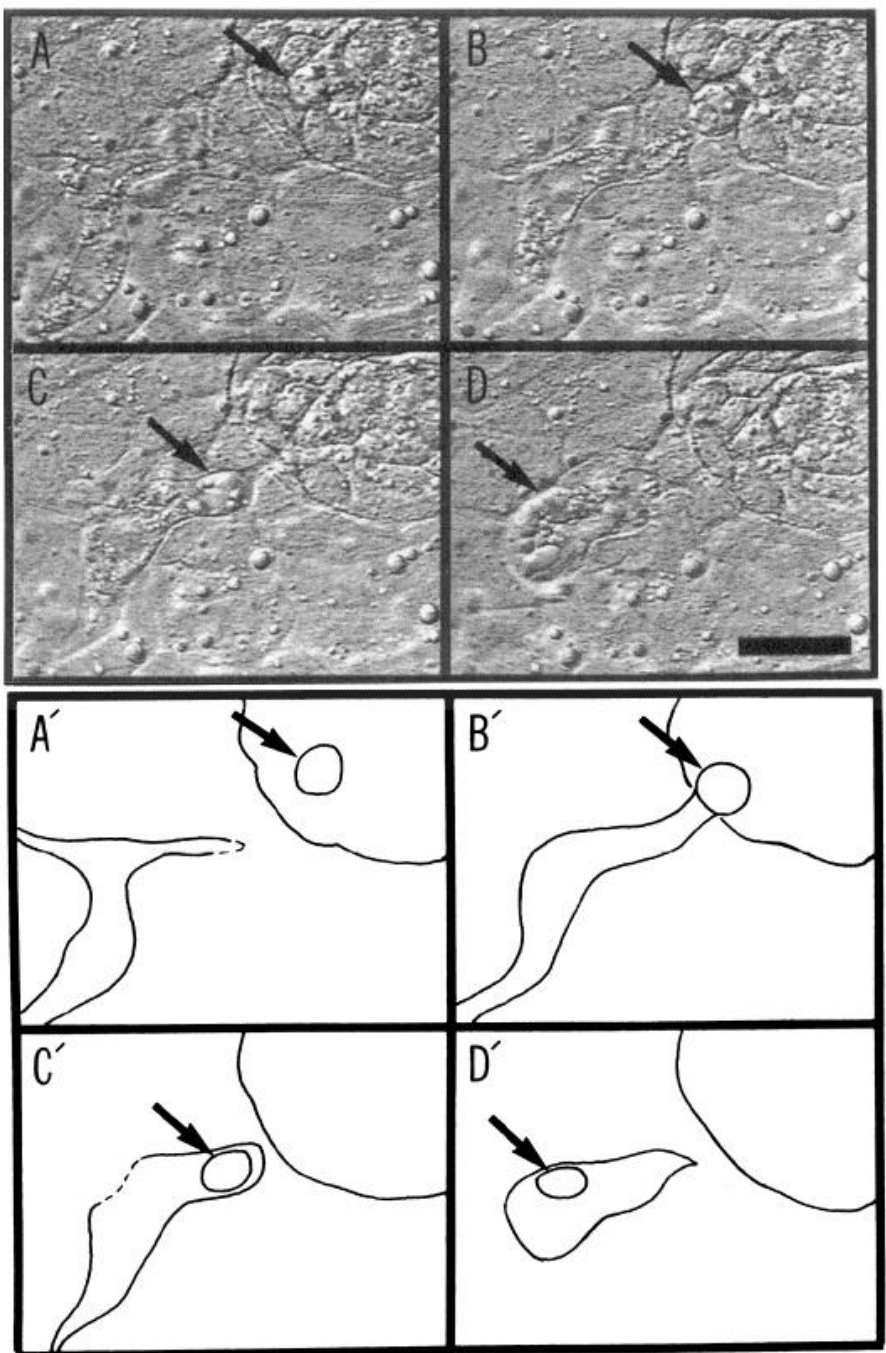

Figure 11. Morphology and phagocytic behavior of a "large" leukocyte. $A-D$, The appearance in the time-lapse video record of the posterior edge of a neuromast, and a large phagocytic leukocyte. The arrows indicate the position of the nucleus of an internal supporting cell originally located within the neuromast. $A^{\prime}-D^{\prime}$, Profiles of the large leukocyte, the border of the neuromast, and the outline of the nucleus of the supporting cell targeted for phagocytosis are shown schematically for each of the DIC video micrographs in $A-D$. Over the course of approximately $1 \mathrm{hr}$, the large leukocyte migrated into the field of view, extended a pseudopodium into the neuromast, and removed the supporting cell from the epithelium.

on the fifth day after amputation, the numbers of leukocytes had decreased sharply so that they approached the numbers present at the time of amputation. Those numbers increased slightly at the time of the fifth and last sample point, seven days following amputation.

\section{Discussion}

The results conclusively demonstrate that the cells of the regenerative placode arise from divisions of supporting cells in the posteriormost neuromast that remains on the tail stump following amputation of the tip of the tail. The divisions of mantle-type supporting cells were observed to produce progeny that formed the initial regenerative placode. Since we made observations over finite periods of several days in most cases, using light microscopic methods, we cannot completely rule out

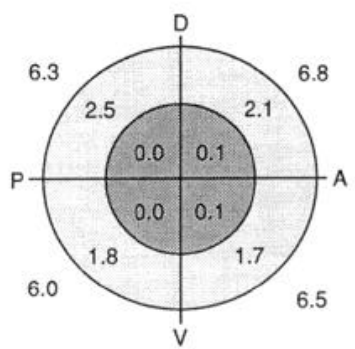
Leukocytes
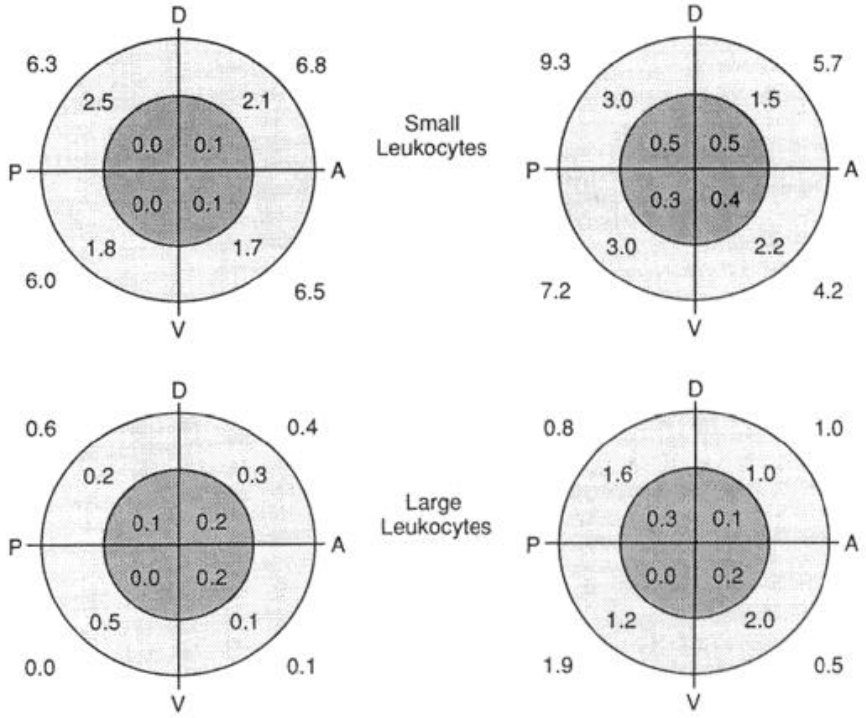

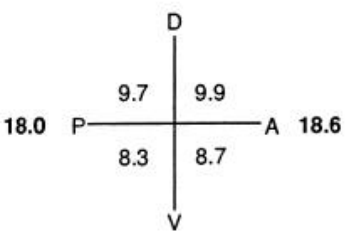

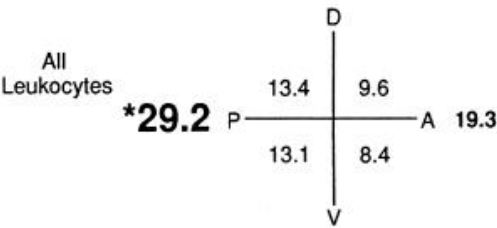

Figure 12. Leukocyte redistribution in lateral line sensory epithelia following tail-tip amputation. Internal and mantle-type supporting cell populations are depicted as in Figure 5, with the addition of data for the tissue peripheral to the neuromasts (region outside of the outer circle). Control, Data from the initial $24 \mathrm{hr}$ of time-lapse observation in six salamanders (total of $144 \mathrm{hr}$ of observation), averaged to a $12 \mathrm{hr}$ period of observation. After Tail Amputation, Data from the initial $72 \mathrm{hr}$ of time-lapse observation in four salamanders (total of $288 \mathrm{hr}$ of observation), averaged to a $12 \mathrm{hr}$ period of observation. Numbers in the bottom pair of drawings represent the combined averages for small and large leukocytes for each of the four quadrants. Bold numbers represent the average number of leukocytes observed in the posterior and the anterior halves of the neuromasts and their immediate periphery. ${ }^{*}, p$ $<0.01$, Student's $t$ distribution.

the possibility that some cells that enter the regenerative placodes might occasionally originate as the progeny from divisions of internal supporting cells, but we did not find any positive evidence for that during our observations. Similarly, we never observed any contribution to the placodes from epidermal cells or the progeny of epidermal cell divisions. Placodal cells con-

Table 2. Phagocytosis by large leukocytes (average number observed per $12 \mathrm{hr}$ time-lapse interval)

\begin{tabular}{lll} 
& Treatment & \\
\cline { 2 - 3 } Cell type & Control & $\begin{array}{l}\text { Tail-tip } \\
\text { amputation }\end{array}$ \\
\hline Internal SC & $0.3 \pm 0.2$ & $0.2 \pm 0.2$ \\
Mantle-type SC & $0.2 \pm 0.2$ & $0.9 \pm 0.2^{*}$ \\
Hair cell & 0 & $0.1 \pm 0.2$ \\
\hline
\end{tabular}

SC, supporting cell.

${ }^{*} p<0.01$, Student's $t$ distribution. 

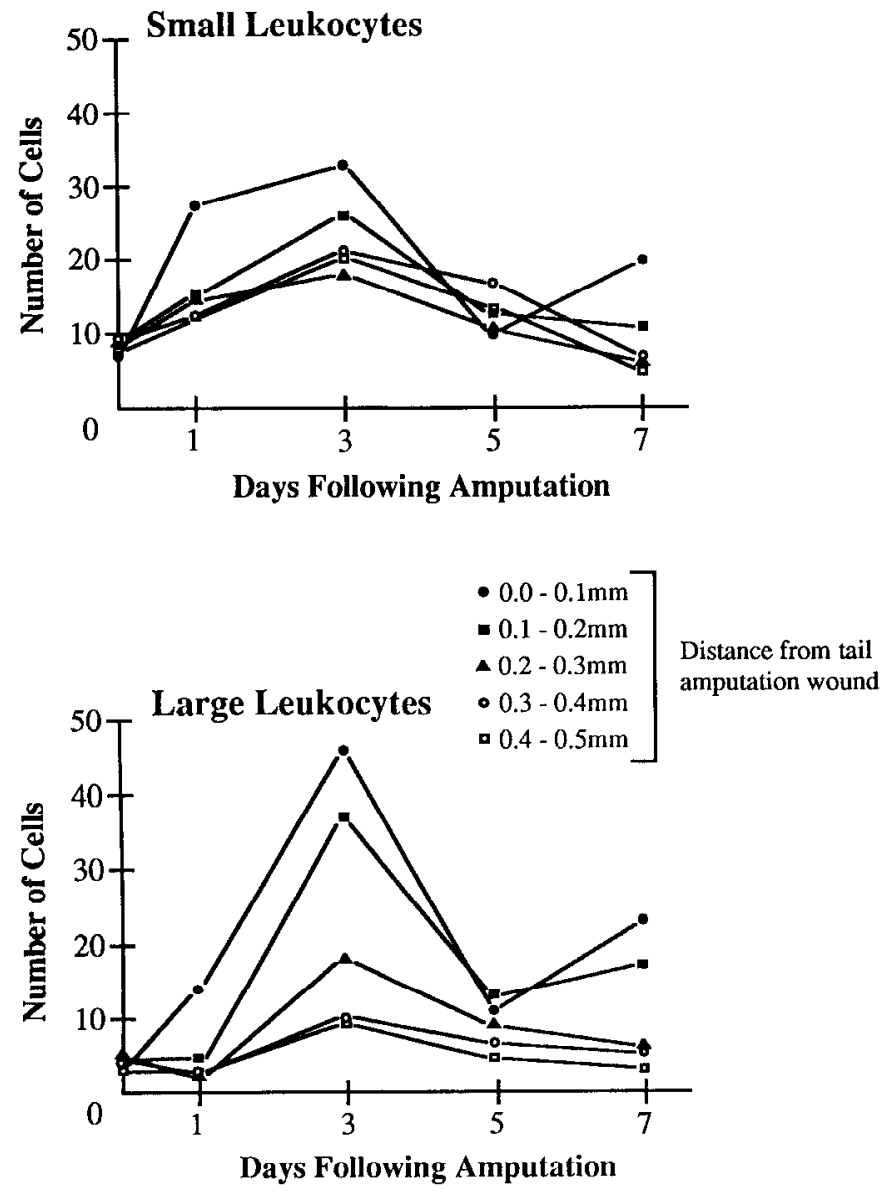

Figure 13. Tissue-wide responses of leukocytes to the wound created by amputating the tip of the tail. Four tails were fixed within $10 \mathrm{~min}$ after amputation and at 1, 3, 5, and $7 \mathrm{~d}$ after amputation. Samples were stained sequentially for chloroacetate esterase and myeloperoxidase localization in leukocytes. The positions of all the leukocytes were charted on a camera lucida drawing of each tail. Small and large leukocytes (granulocytes and macrophages, respectively) were counted separately in five vertical bands $0.1 \mathrm{~mm}$ wide by $2 \mathrm{~mm}$ long that began at the site of tail amputation and continued anteriorly.

tinue to divide and migrate posteriorly where their progeny eventually differentiate into new hair cells and supporting cells in replacement neuromasts. Thus, supporting cells can function as the early progenitor in a lineage that gives rise not only to replacement supporting cells, but also to replacement hair cells.

The proliferative response of mantle-type supporting cells is restricted to those cells in the posteriormost neuromast on the tail stump, and most noticeably affects cells at the posteroventral edge of that neuromast. This localized mitotic response suggests that the triggering mechanism is not systemically humoral. Consistent patterns of mantle-type supporting cell proliferation occur in neuromasts that are participating in lateral line regeneration. The greatest numbers of cell divisions are in the posteroventral quadrant of the neuromast. Intermediate numbers of divisions occur in the posterodorsal quadrant, and fewer occur in the two anterior quadrants (Fig. 4). The consistent pattern of those cell divisions suggests that a source of mitogenic triggering activity could be located posterior and ventral to the neuromast. Several axial structures that are posterior and ventral to regenerating neuromasts are cut when the tip of the tail is amputated. These include the lateral line nerve, the spinal cord, the caudal artery and caudal vein, the vertebral column, and the axial musculature. As tail regeneration proceeds, a blastema forms on the tail stump posterior and ventral to the responding neuromasts (Fig. 1). Recent evidence indicates that the blastema that is formed during regeneration of the axolotl limb produces acidic fibroblast growth factor (aFGF; Boilly et al., 1991). The production of aFGF or similar growth factors by cells in the blastema that forms on the tail stump aftcr amputation could contribute to development of the pattern of mantle cell proliferation that we have observed. At present, however, the data do not allow us to make conclusive statements about any candidate effectors that might regulate the proliferation of the mantle-type supporting cells.

During regeneration, the mantle-type supporting cells increase their rates of division and the internal supporting cells decrease their rates of division. This differential response in two closely related populations of cells is unexplained. Mantle-type supporting cells and internal supporting cells may respond to two different regulatory signals that have opposite effects on cell proliferation. Alternatively, mantle-type supporting cells and internal supporting cells may be responding to the same regulatory signal(s), but with opposite sign. For example, transforming growth factor- $\beta$ (TGF- $\beta$ ) is known to exert both stimulatory and inhibitory effects on cell proliferation (Sporn et al., 1986). The data from the lateral line system currently do not distinguish between these possibilities.

Time-lapse recording and histochemical staining have demonstrated that leukocytes are numerous and intensely active in the epidermis and the lateral line neuromasts of the axolotl tail under control conditions. The small leukocytes in those tissues are primarily monocytes and neutrophilic granulocytes. The large leukocytes are mostly mature macrophages.

Both types of leukocytes redistribute in response to tail amputation wounding (Figs. 12, 13). Small granulocytes rapidly accumulate near the wound site. Their numbers approached a maximal level during the second sampling period, $24 \mathrm{hr}$ after amputation (Fig. 13). This finding is consistent with previous reports of rapid granulocyte chemotaxis toward byproducts of tissue wounding such as complement fragments (Bjork et al., 1983 ) and $N$-formyl peptides produced by bacteria (Colditz and Movat, 1984). Neutrophilic granulocytes are thus likely to serve in a first line of defense against bacterial infection near the site of a wound in the salamander as do their counterparts in other species (Tonnesen et al., 1988).

Large macrophages also accumulate near the wound beginning as early as $24 \mathrm{hr}$ after tail-tip amputation, but the macrophage response appears to be larger in magnitude and slower to reach its peak. Substantially greater numbers of macrophages were present near the wound on the third day following amputation as compared with $24 \mathrm{hr}$ after amputation (Fig. 13). Like granulocytes, macrophages are known to show directed migration in vitro in response to complement fragments (Marder et al., 1985), and fragments of extracellular matrix components such as collagen (Postlethwaite and Kang, 1976) and fibronectin (Norris et al., 1982).

The concept of macrophages as simple scavengers of cellular debris has been modified in recent years, in part because macrophages have been found to secrete a wide variety of biologically active compounds with effects that range from stimulating cell proliferation to causing cell death (Nathan, 1987). Macrophages appear to play a pivotal role in other types of wound healing (Leibovich and Ross, 1975; Hunt et al., 1984; Riches, 
1988). By the third day following tail amputation wounding, macrophages are present at more than 11 times the numbers at the time of amputation (Fig. 13). The increase in the occurrence of macrophages in the tissues around the neuromast that is nearest to the site of the amputation wound immediately precedes the onset of placode-forming mitotic activity in the mantle cells that are in the posterior half of the neuromast, nearest to the site of the wound. The ability of macrophages to secrete mitogenic growth factors is of interest because of the possibility that the proliferation of supporting cells might be influenced by those secretions during lateral line regeneration. The specific mitogenic growth factors that have been shown to be produced by macrophages in other systems include basic fibroblast growth factor (Baird et al., 1985), platelet-derived growth factor (Shimokado et al., 1985), and a heparin-binding form of epidermal growth factor (HB-EGF; Higashiyama et al., 1991). Macrophages isolated from wounds also have been found to contain mRNA transcripts for TGF $-\alpha$ and TGF- $\beta$ (Rappolee et al., 1988). The potential secretion of mitogens that influence cells of ectodermal origin (HB-EGF and TGF- $\alpha$ ) is of particular interest because of the ectodermal origin of hair cell epithelia. EGF has been shown to stimulate the proliferation of multipotent cells isolated from the adult mouse brain, and the progeny of those divisions can differentiate to separately express markers of neuronal and glial specialization (Reynolds and Weiss, 1992).

Macrophages could potentially affect mantle cell proliferation by means that are independent of their potential secretion of growth factors. Ultrastructural studies have shown that the outer surfaces of mantle-type supporting cells in lateral line epithelia are covered with material that stains densely with ruthenium red (Hama, 1978). We presume that this glycocalyx is compused of proteoglycan, as evidenced by labeling with peanut agglutinin (J. E. Jones and J. T. Corwin, unpublished observation). An intact glycocalyx on the surfaces of mantle-type supporting cells in the axolotl might serve to restrict their proliferation by preventing the cells from migrating out of the neuromast, where they would be released from contact inhibition of mitosis (Holley and Kiernan, 1968). Chondroitin sulfate proteoglycan has recently been shown to limit cell migration during development of the retina (Brittis et al., 1992), and a boundary with peanut agglutinin-binding activity exerts negative control over migration of neural crest cell in the dorsolateral pathway during development (Lasky et al., 1991). The presence of a thick intact glycocalyx also might conceal the binding sites of growth factor receptors that could be present on the surfaces of mantle-type supporting cells. The extensive glycocalyx that envelopes endothelial cells has been proposed to have such a molecular sieving function (Ryan and Ryan, 1984). Macrophages secrete glycosidases that could break down the carbohydrate residues of a glycocalyx (Takemura and Werb, 1984; Nathan, 1987). Glycosidase secretion by the macrophages that accumulate near neuromasts participating in lateral line regeneration could break down a glycocalyx on mantle-type supporting cells, and that could release the cells from mechanical inhibition of migration and growth or expose covert receptors for growth factors.

Once the mantle-type supporting cells divide, their progeny rapidly move to the site of the future regenerative placode, where they begin to divide more rapidly. The dramatic increase in the number of growing cells within the well-defined dorsal and ventral boundaries of the regenerative placode accounts for a significant portion of its posteriorward advance, but individual placodal cells are also motile. Placodal cells migrate indepen- dently of one another, similar in that sense to the independent motility of neural crest cells and leukocytes in vivo (Trinkaus, 1984). The mode of locomotion of placodal cells differs from the amoeboid locomotion of leukocytes in this tissue, and the tractor-like locomotion that has been described in studies of the lead cells of advancing epithelial sheets during the healing of epidermal wounds in epidermis. Placodal cell locomotion observed in our recordings may differ from the lamellipodia-based locomotion of fibroblasts and nerve growth cones in vitro, because expansive lamellae were not visible. The placodal cells appear to maintain relatively stable overall shapes while undergoing membrane "ruffling" (cf. Abercrombie et al., 1970).

The cells of the regenerative placode appear to follow a restricted path of migration over the basal lamina, similar to the migratory path of the embryonic lateral line primordia observed in axolotl salamanders (Smith et al., 1990) and in zebrafish (Metcalfe, 1985). In other systems, the molecular makeup of the extracellular matrix influences patterns of cell migration. For example, the pathways of neural crest migration during development are at least partially determined by the distribution of the extracellular matrix glycoproteins fibronectin, laminin, and tenascin (Bronner-Fraser, 1986; Mackie et al., 1988). It is possible that placodal cells are similarly inhibited and guided in their migration by the molecular makeup of the extracellular matrix and basal lamina of the newly regenerating tail, but that was not investigated in this study.

The time-lapse video recording technique described in this report has advantages over some previous means of time-lapse microscopy. Recording of microscopic images onto optical disks rather than videotape allows a drastic reduction in the duty cycle of microscopic illumination. This proved to be a crucial step for having lateral line regeneration proceed normally under time-lapse conditions. Optical disk recording allowed a random access to the images, a feature that greatly facilitated the analysis of the results. Finally, the use of a computer controlled motor to change to several levels of focus repeatedly, combined with time-lapse recording at each of those levels of focus, allowed concurrent recording of the behavior of all the cells in the threedimensional epithelia that were the subject of the study, and greater confidence in the results.

\section{References}

Abercrombie M, Heaysman M, Pegrum SN (1970) The locomotion of fibroblasts in culture. Exp Cell Kes 60:437-444.

Baird A, Mormede P, Bohlen P (1985) Immunoreactive fibroblast growth factor in cells of peritoneal exudate suggests its identity with macrophage-derived growth factor. Biochem Biophys Res Commun 126:358-364.

Balak KI, Corwin IT, Jones IE (1990) Regenerated hair cells can originate from supporting cell progeny: evidence from phototoxicity and laser ablation experiments in the lateral line system. J Neurosci 10:2502-2512.

Bjork J, Hugli TE, Snedegard G (1983) Microvascular effects of anaphylatoxins C3a and C5a. J Immunol 134:1115-1119.

Boilly B, Cavanaugh KP, Thomas D, Hondermarck $H$, Bryant SV, Bradshaw RA (1991) Acidic fibroblast growth factor is present in regenerating limb blastemas in axolotls and binds specifically to blastema tissues. Dev Biol 145:302-310.

Bredberg G (1968) Cellular pattern and nerve supply of the human organ of Corti. Acta Otolaryngol [Suppl] (Stockh) 236:1-135.

Brittis PA, Canning DR, Silver J (1992) Chondroitin sulfate as a regulator of neuronal patterning in the retina. Science 255:733-736.

Bronner-Fraser M (1986) An antibody to a receptor for fibronectin and laminin perturbs cranial neural crest development in vivo. Dev Biol 117:528-536. 
Colditz IG, Movat HZ 984) Kinetics of neutrophil accumulation in acute inflammatory lesions by chemotaxis and chemotaxinogens. J Immunol 133:2169-2173.

Corwin JT (1981) Postembryonic production and aging of inner ear hair cells in sharks. J Comp Neurol 201:541-553.

Corwin JT (1983) Postembryonic growth of the macula neglect auditory detector in the ray, Raja clavata: continual increases in hair cell number, neural convergence, and physiological sensitivity. J Comp Neurol 217:345-356.

Corwin JT (1985) Perpetual production of hair cells and maturational changes in hair cell ultrastructure accompany postembryonic growth in an amphibian ear. Proc Natl Acad Sci USA 82:3911-3915.

Corwin JT (1986) Regeneration and self-repair in hair cell epithelia: experimental evaluation of capacities and limitations. In: The biology of change in otolaryngology (Ruben RJ, Van DeWater TR, and Rubel EW, eds), pp 291-304. New York: Elsevier.

Corwin JT, Cotanche DA (1988) Regeneration of sensory hair cells after acoustic trauma. Science 240:1772-1774.

Corwin JT, Balak KJ, Borden PC (1989) Cellular events underlying the regenerative replacement of lateral line sensory epithelia in amphibians. In: The mechanoscnsory lateral line: neurobiology and evolution (Coombs S, Görner P, Münz H, eds), pp 161-183. New York: Springer.

Flock $\AA$ (1965) Electron microscopic and electrophysiological studies on the lateral line canal organ. Acta Otolaryngol [Suppl] (Stockh) 199: $1-90$.

Flock $\AA$, Jørgensen JM (1974) The ultrastructure of lateral line sense organs in the juvenile salamander, Ambystoma mexicanum. Cell Tissue Res 152:283-292.

Flock $\AA$, Jørgensen JM, Russell IJ (1973) The physiology of individual hair cells and their synapses. In: Basic mechanisms of hearing (Møller AR, ed), pp 273-306. New York: Academic.

Fritzsch B, Wahnschaffe U (1987) Electron microscopical evidence for common inner ear and lateral line efferents in urodeles. Neurosci Lett 81:48-52.

Hadji-Azimi I, Coosemans V, Canicatti C, Perrenot N (1987) Atlas of adult Xenopus laevis hematology. Dev Comp Immunol 11:807874

Hama K (1978) A study of the fine structure of the pit organ of the common Japanese sea eel Conger myriaster. Cell Tissue Res 189: 375-388.

Higashiyama S, A braham JA, Miller J, Fiddes JC, Klagsburn M (1991) A heparin-binding growth factor secreted by macrophages and macrophage-like cells that is related to EGF. Science 251:936-939.

Holley RW, Kiernan JA (1968) "Contact inhibition" of cell division in 3 T 3 cells. Proc Natl Acad Sci USA 60:300-304.

Hudspeth AJ (1985) The cellular basis of hearing: the biophysics of hair cells. Science 230:745-752.

Hunt T, Knighton DR, Thakral KK, Goodson WH, Andrews WS (1984) Studies on inflammation and wound healing: angiogenesis and collagen synthesis stimulated in vivo by resident and activated wound macrophages. Surgery $96: 48-54$.

Jørgensen JM, Flock $\AA$ (1973) The ultrastructure of lateral line sense organs in the adult salamander Ambystoma mexicanum. J Neurocytol 2:133-142.

Jørgensen JM, Mathiesen C (1988) The avian inner ear. Continuous production of hair cells in vestibular organs, but not in the auditory papilla. Naturwissenschaften 75:319-320.

Kaplow LS (1965) Simplified myeloperoxidase stain using benzidine dihydrochloride. Blood 26:215-219.

Kimura RS (1975) The ultrastructure of the organ of Corti. Int Rev Cytol 42:173-222.

Landacre FL (1921) The fate of the neural crest in the head of urodeles. J Comp Neurol 33:1-43.

Lasky C, Oakley RA, Dehnbostel D, Tosney KW (1991) Experimental evidence that an inhibitory boundary delays neural crest cell migration. Soc Neurosci Abstr 17:761.

Leibovich SJ, Ross R (1975) The role of the macrophage in wound repair. A study with hydrocortisone and antimacrophage serum. Am J Pathol 78:71-100.

Li CY, Lam KW, Yam LT (1973) Esterases in human leukocytes. J Histochem Cytochem 21:1-12.

Mackie EJ, Tucker RP, Lalfter W, Chiquet-Ehrismann R, KH Epperlein
(1988) The distribution of tenascin coincides with pathways of neural crest migration. Development 102:237-250.

Marder SR, Chenoweth DE, Goldstein IM, Perez HD (1985) Chemotactic responses of human peripheral blood leukocytes to the complement-derived peptides C5a and C5a des-Arg. J Immunol 134: $3325-3334$.

Meredith GE, Roberts BL (1987) Distribution and morphological characteristics of efferent neurons innervating end organs in the ear and lateral line of the European eel. J Comp Neurol 265:494-506.

Metcalfe W (1985) Sensory neuron growth cones comigrate with posterior lateral line primordial cells in zebrafish. J Comp Neurol 238: 218-224.

Nathan CF (1987) Secretory products of macrophages. J Clin Invest 79:319-326.

Norris DA. Clark RAF. Swigart LM, Huff JC. Weston WL, Howell SE (1982) Fibronectin fragment(s) are chemotactic for human peripheral blood monocytes. J Immunol 129:1612-1618.

Popper AN, Hoxter B (1984) Growth of a fish ear. I. Quantitative analysis of hair cell and ganglion cell proliferation. Hear Res 46:922.

Postlethwaite AE, Kang AH (1976) Collagen- and collagen-peptide induced chemotaxis of human blood monocytes. J Exp Med 143: 1299-1307.

Rappolee SA, Mark D, Banda MJ, Werb Z (1988) Wound macrophages express TGF- $\alpha$ and other growth factors in vivo: analysis by mRNA phenotyping. Science 241:708-712.

Reynolds BA, Weiss S (1992) Generation of neurons and astrocytes from isolated cells of the adult mammalian central nervous system. Science 255:1707-1710.

Riches DWH (1988) The multiple roles of macrophages in wound healing. In: The molecular and cellular biology of wound repair (Clark RAF, Henson PM, eds), pp 213-239. New York: Plenum.

Ruben RJ (1967) Development of the inner ear of the mouse: a radioautographic study of terminal mitoses. Acta Otolaryngol [Suppl] (Stockh) 220:1-44.

Ryals BW, Rubel EW (1988) Hair cell regeneration after acoustic trauma in adult Coturnix quail. Science 240:1774-1776.

Kyan US, Kyan JW (1984) The ultrastructural basis of endothelial cell surface functions. Biorheology 21:155-170.

Shimokado K, Raines EW, Madtes DK, Barrett TB, Benditt EP, Ross $R$ (1985) A significant part of macrophage-derived growth factor consists of at least two forms of PDGF. Cell 43:277-288.

Smith SC, Lanoo MJ, Armstrong JB (1990) Development of the mechanoreceptive lateral-line system in the axolotl: placode specification, guidance of migration, and the origin of neuromast polarity. Anat Embryol (Berl) 182:171-180.

Speidel CC (1947) Correlated studies of sense organs and nerves of the lateral-line in living frog tadpoles. J Comp Neurol 87:29-55.

Sporn MB, Roberts AB, Wakefield WM, Assoian RK (1986) Transforming growth factor $\beta$ : biological function and chemical structure. Science 233:532-534.

Stone LS (1922) Experiments on the development of the cranial ganglia and the lateral line sense organs in Amblystoma punctatum. J Exp Zool 35:421-496.

Stone LS (1933) The development of lateral-line sense organs in amphibians observed in living and vital-stained preparations. J Comp Neurol 57:507-540.

Stone LS (1937) Further experimental studies of the development of lateral line sense organs in amphibians observed in living preparations. J Comp Neurol 68:83-115.

Takemura K, Werb Z (1984) Secretory products of macrophages and their physiological function. Am J Anat 246:C1-C9.

Tonnesen MG, Worthen GS, Johnston RB (1988) Neutrophil emigration, activation, and tissue damage. In: The molecular and cellular biology of wound repair (Clark RAF, Henson PM eds), pp 213-239. New York: Plenum.

Trinkaus JP (1984) Cells into organs. The forces that shape the embryo, 2d ed. Englewood Cliffs, NJ: Prentice-Hall.

Turner RJ (1988) Amphibians. In: Vertebrate blood cells (Rowley AF, Ratcliffe NA, eds), pp 129-209. Cambridge: Cambridge UP.

Wright MR (1947) Regeneration and degeneration experiments on lateral line nerves and sense organs in anurans. J Exp Zool 105:221257. 